\title{
La relación procesal entre órganos de Administración de Justicia y Tribunales de Arbitraje
}

Edgar Neira Orellana (*)

\section{Sumario}

1. Introducción. 2. REPSOL-SOCIETYSEG Cía. Ltda.: Un Caso Paradigmático sobre la Alternabilidad del Arbitraje. 3. Alternabilidad del arbitraje y derecho comparado. 3.1 La Ley Modelo CNUDMI/UNCITRAL. 3.2 La Ley de Arbitraje Española. 3.3 La nueva Ley Peruana de Arbitraje. 3.4 La Ley de Arbitraje de Colombia. 4. La alternabilidad del arbitraje en la legislación ecuatoriana. 4.1 Los árbitros no son órganos de la Función Judicial del Estado. 5. Antijuridicidad de los "anuncios de competencia" de un juez ordinario a un Tribunal de Arbitraje. 5.1 Casos en que un Juez puede entablar una relación procesal con un Tribunal de Arbitraje. 5.2 El caso HAMPTON COURT RESOURCES ECUADOR: un precedente peligroso para el sistema arbitral ecuatoriano. 5.2.1 Comentario a la sentencia del juicio de competencia planteado por HAMPTON COURT RESOURCES ECUADOR. 6. Conclusión.

\section{INTRODUCCIÓN}

El presente análisis se suma a la iniciativa del Instituto Ecuatoriano de Arbitraje, de rendir un homenaje al Dr. Carlos Larreátegui Mendieta, abogado y jurista que iluminó con sus reflexiones los primeros momentos del arbitraje comercial en el año 1963, y lo ha seguido haciendo hasta nuestros días en calidad de árbitro del Centro de Arbitraje y Mediación de la Cámara de Comercio de Quito. 
El Dr. Carlos Larreátegui, a esa fecha Director Ejecutivo de la Cámara de Comercio, impulsó la publicación de los Cuadernos de Divulgación Comercial y contribuyó a difundir la Ley de la materia, mediante un esclarecedor análisis sobre las ventajas del arbitraje frente a los procesos ventilados ante la justicia ordinaria. Con citas pertinentes de Bernardo Cremades y de Nills Mangard, destacó que al sistema arbitral se le atribuye: 1) celeridad, 2) menor costo en función del tiempo de tramitación, 3) ausencia o atenuación de formalismo, 4) mayor acierto en los fallos, 5) mayor flexibilidad en el procedimiento, 6) eliminación de conflictos jurisdiccionales, 7) reserva y, 8) estabilidad de las relaciones comerciales.

No obstante que a esta fecha, la promoción del arbitraje viene auspiciada por la expedición de la Ley de Arbitraje y Mediación de 1997, enriquecida por la Ley Modelo de la CNUDMI/UNCITRAL, por el reconocimiento constitucional del sistema desde el año 1998 y el notable desempeño de varios Centros de Arbitraje que funcionan en el país, se ha vuelto indispensable reiterar en la invocación de tales ventajas que el Dr. Larreátegui Mendieta las señaló en los años 60, a partir de un examen sobre la característica más singular que distingue al arbitraje frente a la administración de justicia ordinaria: su alternabilidad y la consecuente restricción en la comunicación procesal entre árbitros y jueces, más aun cuando desafortunadas actuaciones de ciertos órganos jurisdiccionales a partir de agosto de 2011, pretenden desandar todo el camino que en esta materia ha recorrido el sistema arbitral del Ecuador, desde febrero de 2005.

\section{REPSOL-SOCIETYSEG CÍA. LTDA.: UN CASO PARADIGMÁTICO SOBRE la alternabilidad del Arbitraje}

Este análisis tiene origen en las reflexiones que por primera vez me correspondieron plantear dentro del caso arbitral REPSOL-SOCIETYSEG que se tramitó ante el Centro de Arbitraje y 
Mediación de la Cámara de Comercio de Quito y a la decisión que, en calidad de árbitro único me correspondió adoptar con fecha 16 de febrero de 2005.

En condición de árbitro único declaré tener competencia para conocer de ese litigio, sobre la base de un convenio que habían suscrito las mencionadas partes ${ }^{1}$, en que habían acordado someter "cualquier" diferencia a la competencia "exclusiva" de un Tribunal de Arbitraje.

Frente a la declaratoria de competencia hecha en la audiencia de sustanciación, la parte insatisfecha con tal declaratoria planteó una acción inhibitoria ante los Jueces de lo Civil de Pichincha, al amparo del Art. 848 y siguientes del Código de Procedimiento Civil. La parte argumentó incompetencia del árbitro para resolver la controversia arbitral y fue acogida por el Juez Suplente en un primer momento, con desconocimiento del carácter alternativo del arbitraje.

Radicada la causa por sorteo ante el Juez Décimo Primero de lo Civil éste acogió la demanda y remitió un oficio en que anunció su competencia y solicitó que me inhiba de conocer la causa arbitral. Después de la respuesta enviada al Juzgado en que en calidad de árbitro aclaré al Juez Civil que los conflictos de competencia regulados por el Código de Procedimiento Civil son aplicables entre órganos de la Función Judicial y que no se extienden a Tribunales de Arbitraje, que los casos en que se puede trabar una relación procesal entre jueces y árbitros son los expresamente establecidos en la Ley de Arbitraje y Mediación y que en virtud del principio kompetenz-kompetenz solamente a los árbitros les corresponde pronunciarse sobre su propia competencia.

1. El Art. 22 de la Ley de Arbitraje y Mediación establece el principio kompetenz-kompetenz según el cual solamente a los árbitros corresponde declarar sobre su propia competencia, sin que ningún órgano jurisdiccional ni de otra naturaleza pucda interferir en tal declaratoria. En el señalado caso, la declaratoria de competencia se la habia hecho mediante providencia de 19 de enero del 2005, fundamentado en un Contrato de Servicios Gencrales suscrito por las partes, cuya clảusula 19 señalaba con carácter "irrevocable" someter a la jurisdicción "exchusiva" de un Tribunal de Arbitrajc "cualquier disputa. contrnersia o reclamo que derive del contrato o que tenga relación con él". 
Sobre la base de esta respuesta, el Juez Civil acertó en revocar el anuncio de competencia que había realizado previamente y mediante auto de 4 de marzo de 2005 declaró la nulidad de todo lo actuado, porque consideró que al haberse declarado previamente la competencia por parte del árbitro, el juez no puede entrar a conocer de la demanda arbitral.

La parte accionante del juicio de competencia presentó un recurso de apelación el que fue conocido y resuelto por la Primera Sala de lo Civil de la Corte Superior de Justicia, integrada por los Ministros Jueces doctores Alberto Palacios Durango, Presidente de la Sala, Jorge Ortiz B. y Ramiro Suárez Almeida. La mencionada Sala, en un memorable fallo de 27 de enero de 2006, negó la apelación que se había propuesto contra la decisión del Juez inferior y con apropiados razonamientos sustentó su decisión en los principios que inspiran al arbitraje.

El fallo de la Corte Provincial se revistió de argumentos de derecho irrefutables y apeló a varios principios que inspiran al arbitraje en el Ecuador. Razonó sobre las "diferencias profundas" entre la jurisdicción de los jueces ordinarios cuyas atribuciones nacen de la ley, y el arbitraje cuya fuente inmediata de atribuciones es el acuerdo de las partes. En la opinión de los Ministros de la Sala, de ese hecho derivan varias consecuencias jurídicas, una de ellas la necesaria separabilidad de la cláusula de compromiso arbitral respecto del contrato en que está inserta; y el principio de competencia de la competencia, esto es, "la capacidad de los árbitros para decidir acerca de su propia competencia, cuando esta es cuestionada"2.

2. En el considerando TERCERO de ia sentencia, la Sala de lo Civil y Mercantil, con relación al principio "kompetenz-kompetenz" motivó su decisión asi: "Este principio está reconocido en ntestro ortenumiento juridico en el Art. 22 de la Ley de Arbitraje y Afediacioin. que estipula que el Tribunal en la Audiencia de Sustanciación 'resolverá sobre su propia competencia' y csta norma tiene estrecha relacioin con la 'excepciän del convenio arhitral" prescrita en el Art. 8 de la Lay de Arbitraje y Mediación... En la especie se aprecia que la competencia ha sido resuelta por el Arbitro tinico designado. quien ya se declaró competente en la Audiencia de Sustanciación sin que esfa pueda posteriormente ser disputada". 
La decisión de la Corte Superior de Pichincha en el caso REPSOL-SOCIETYSEG, aparentemente resolvió este debate y aclaró desde el año 2006 los fundamentos sobre los que se erige el sistema arbitral. Sin embargo, cinco años después, la Primera Sala de lo Civil y Mercantil de la Corte Provincial de Justicia de Pichincha, mediante un desafortunado fallo de 31 de agosto de 2011 expedido dentro del juicio de competencia seguido por la compañía HAMPTON COURT RESOURCES en contra de un Tribunal de Arbitraje, se apartó de la doctrina sentada por esa Corte desde el año 2006 y aceptó el anuncio de competencia del Juez Civil a un Tribunal de Arbitraje.

Al menos dos preguntas podrían formularse a partir de estos eventos procesales con decisiones contradictorias: la primera ${ }_{i}$ Por qué es juridicamente inadmisible que un juez ordinario anuncie su competencia a un Tribunal de Arbitraje después de que éste ha declarado tenerla para conocer y resolver un determinado caso?, ¿Está autorizado un Tribunal de Arbitraje que ha declarado su competencia para resolver una controversia, suspender su tramitación para remitir el proceso a un órgano de la Función Judicial?

Para responder esas preguntas es necesario definir previamente la alternabilidad del arbitraje a partir del derecho comparado, de las normas del sistema legal vigente en Ecuador y, posteriormente, explicar las consecuencias jurídicas que derivan de ésta.

\section{Alternabilidad del arbitraje $Y$ DERECHO COMPARADO}

Este acápite pretende describir brevemente cómo las legislaciones de España, Perú y Colombia, -que al igual que la ecuatoriana se inspiran en la Ley Modelo de la CNUDMI/UNCITRAL-, regulan la relación de los árbitros con los órganos jurisdiccionales $y$, establecer si existe o no prohibición a que se produzcan interferencias judiciales en el trámite de los juicios arbitrales. 
Según se analizará a continuación, el impedimento a la interferencia de los jueces sobre el arbitraje, constituye uno de los instrumentos procesales más idóneos para precautelar la alternabilidad del método compositivo frente al juez ordinario cuyo reconocimiento ha sido ampliamente regulado en todos los ordenamientos legales. La sentencia del caso REPSOL-SOCIETYSEG confirmó esta posición.

Para una cabal comprensión de las leyes de España, Perú y Colombia, consideré pertinente introducir una referencia sumaria de la Ley Modelo de la CNUDMI/UNCITRAL, por ser la inspiradora de esas legislaciones y por el notable influjo que tuvo sobre el texto de la ley vigente en Ecuador.

\subsection{La Ley Modelo CNUDMI/UNCITRAL}

La Ley Modelo sobre Arbitraje Comercial de la Comisión de las Naciones Unidas para el Derecho Mercantil Internacional, aprobada el 21 de junio de 1985, plasmó un consenso universal sobre los diversos principios que inspiran la práctica del arbitraje en el mundo. De este modo se constituyó en el resultado de un paulatino proceso de armonización de las leyes nacionales en esta materia, aún en países con distinta tradición jurídica.

La Ley de Arbitraje y Mediación que se expidió en Ecuador en 1997 basa la regulación de sus institutos en la mencionada Ley Modelo. Por ello, el análisis de cómo el derecho comparado trata la alternabilidad del método arbitral impone como primera referencia la Ley Modelo de la CNUDMI/UNCITRAL que presenta reglas categóricas sobre esta materia, de cuyo contenido se desprende que el arbitraje es método alterno y distinto de los procesos que tramitan los órganos jurisdiccionales ordinarios.

El Art. 5 introduce sobre este punto, una disposición de tajante contenido al prever que "en los asuntos que se rijan por la presente Ley, no intervendrá ningún tribunal salvo en los casos en que esta 
Ley asi lo disponga"3. La norma del Art. 8 va más allá al prever el extremo de que cualquier órgano de la justicia ordinaria se abstendrá de tramitar una controversia si esta hubiere quedado sometida a un acuerdo de arbitraje, "a menos que se compruebe que dicho acuerdo es nulo, ineficaz o de ejecución imposible" ${ }^{\prime \prime}$, en cuyo caso y aún cuando esta cuestión se hallare pendiente ante los jueces, nada impedirá que las actuaciones arbitrales inicien o continúen hasta la expedición de un laudo.

Estas normas marcaron una pauta legislativa en un sinnúmero de países, entre ellos el Ecuador. Fijaron una tendencia muy firme para limitar la intervención judicial en el arbitraje y estableció la tesis de que la comunicación procesal entre un órgano jurisdiccional y un Tribunal de Arbitraje solamente puede ocurrir en los casos en que la ley así lo disponga.

\subsection{La Ley de Arbitraje Española}

La Ley de Arbitraje que rige en España ${ }^{5}$ prohíbe la intervención de tribunales y órganos jurisdiccionales en el trámite de un juicio arbitral, con excepción de los casos específicamente previstos en la ley. Esta disposición que trae la ley española de 2003 expresa el carácter alternativo del arbitraje.

De la mano con lo establecido en la Ley Modelo de la CNUDMI, el Art. 8 de la Ley española establece una enumeración

3. Art. 5 de la Ley Modelo de la CNUDMIIUNCITRAL sobre Arbitraje Comercial Internacional (Documentos de las Naciones Unidas A/40/17, ancxo I, y A/6!/17, anexo 1), aprobada el 21 de junio de 1985 y enmendada el 7 julio de 2006 por la Comisión de las Naciones Unidas para el Derecho Mereantil in. ternacional.

4. El texto integro del Art. 8 de la Ley Modelo de la CNUDAIIUNCITRAL tiene el tenor siguiente: "Ar. ticulo 8. Acuerto de arbitraje y demanda en cuanto al fondo ante tun tributal I) El tribunal al que se someta un litigio sobre un astunto que es objeto de un actuendo de arbitraje remitirá a las partes al arbitraje si lo solicita cualquicra de ellas, a mas tardar. en el momenta de presentar el primer escrito sobre ol fondo del litigio, a menos que se conpruebe que dicho acuerdo es mulo, ineficas o de ejecucion imposible. 2) Si se ha entablado la acción a que se refiere el párrafo l) del presente articulo, se podrà. no obstante, iniciar o proseguir las actuaciones arbitrales y dictar un laudo mientras la cuestion csle pendiente ante el tribunal".

5. Ley $60 / 2003$ de 23 de diciembre de Asbitraje, cuyo Art. 7 señala lo siguiente: "Interveneión judicial En los asuntos que se rijan por esta ley no intervendra ninguin tribunal, salvo en los casos en que ésta asi lo disponga". 
taxativa de siete circunstancias procedimentales en que los órganos de administración de justicia pueden intervenir o están llamados a prestar apoyo en el trámite de un arbitraje: la remoción judicial de un árbitro; la asistencia para la práctica de pruebas, la adopción judicial de medidas cautelares, la ejecución forzosa de laudos o resoluciones arbitrales, la anulación de laudos y el reconocimiento de laudos extranjeros.

\subsection{La nueva Ley Peruana de Arbitraje}

Tanto la Ley No. 26572 de Arbitraje que se expidió en 1996 como la nueva ley expedida en el $2008^{6}$ abrazan los principios que en esta materia consagra la Ley Modelo CNUDMI/UNCITRAL. Al igual que la ley anterior, la ley vigente reconoce la alternabilidad del arbitraje y prohíbe a las autoridades jurisdiccionales intervenir en los procesos arbitrales, con excepción de los casos en que la norma de derecho así lo hubiere previsto. Ratifica la independencia de los árbitros con señalamiento de que estos no están sometidos a "orden, disposición o autoridad que menoscabe sus atribuciones".

El numeral 4 del Artículo 3 de la Ley manda que con excepción del recurso de anulación de un laudo, ninguna actuación ni mandato puede afectar, suspender o menoscabar las decisiones de un tribunal arbitral y que cualquier intervención judicial está sujeta a responsabilidad ${ }^{7}$. En otras palabras, el ordenamiento legal

6. Ley de Arbitraje contenida en el Decreto Legislativo No. 1071, publicada el 28 de junio de 2008, vigente en la República del Perú a partit del I de septiembre de ese año. Derogó la anterior Ley General de Arbitraje No. 26572 de 1996 pero la altemabilidad del medio arbitral venia reconocida a través de varias nomas que precautelaban la independencia de los àrbitros y limitaba drásticamente a la intervención del poder judicial a casos especificos previstos en la Ley como son la designación de árbitros por parte de los jueces, en los casos en que hubicre acuerdo de las partes (Arts, 22 y 23); asistencia judicial para la práctica de pruebas (Art. 116) e impugnación de laudos (Art. 123).

Aunque la nueva Ley de Arbitraje contenga disposiciones mejor formuladas al respecto, no se puede desconocer el hecho de que la Ley derogada ya reconoció la plena altemabilidad del arbitraje en el Perú y que esc carácter vino auspiciado por el meritorio papel que desempeñó la jurisprudencia del Tribunal Constitucional. que resolvió en varios casos la plena competencia de los árbitros para conocer y resolver las controversias sometidas al fuero arbitral y rechazó a la interferencia de autoridades judiciales o administrativas en el trámite de los juicios arbitrales.

7. El texto del Articulo $3^{\circ}$ de la Ley de Arbitraje vigente en Perú señala lo siguiente: "Principias y derechos de la fincion arbitral $I$. En los asumos que se rijan por este Decreto Legislatio no intenendra 
peruano ha establecido a favor de la alternabilidad del arbitraje una restricción a la intervención del poder judicial, limitándola al recurso de anulación de laudo y siempre ex post de las actuaciones arbitrales.

\subsection{La Ley de Arbitraje de Colombia ${ }^{8}$}

A diferencia de las leyes de arbitraje del Perú y España, la ley colombiana si califica al arbitraje como un mecanismo "alternativo" de solución de conflictos, pero al igual que todas las que armonizan su contenido con la Ley Modelo de la CNUDMI/UNCITRAL, establece parámetros estrictos de comunicación entre árbitros y jueces, siempre supeditados a una expresa previsión en la Ley de Arbitraje.

El Art. 29 que trata sobre procesos sometidos a la justicia ordinaria, establece que el tribunal de arbitraje es competente para resolver sobre su propia competencia y que las decisiones que los árbitros adoptaren sobre esta materia, prevalecerán sobre cualquier otra expedida por juez ordinario o contencioso administrativos.

la autoridad judicial, salvo en los casos en que exta norma asi lo disponga. 2. El tribunal arbitral tiene plena independencia y no está sometido a orden, disposición o autoridad que menoscabe sus atribuciones. 3. El tribunal arbitral tiene plents atribuciones para iniciar y contimar con el trúmite de las actuaciones arbitrales, decidir acerca de su propia competencia y dictar el laudo. 4 . Ninguna actuación ni mandato fuera de las actuaciones arbitrales podrá dejar sin efecto las decisiones del trihunal arbitral, a excepción del control judicial posterior mediante el recurso de anulación del laudo contemplado en este Decreto Legislativo. Cualquier intenención judicial distimta, dirigida a ejercer un control de las funciones de los árbitros o a interferir en las actuaciones arbitrules antes del laudo. está sujcta a responsabilidad".

8. Ley 1563 publicada en el Diario Oficial de 12 de Julio de 2012 que contiene el Estatuto de Arbitraje Nacional $\mathrm{c}$ Internacional.

9. El Art. $29 \mathrm{de} \mathrm{la} \mathrm{Ley} \mathrm{de} \mathrm{Arbitraje} \mathrm{vigente} \mathrm{en} \mathrm{la} \mathrm{República} \mathrm{de} \mathrm{Colombia} \mathrm{tiene} \mathrm{el} \mathrm{siguiente} \mathrm{tex} \mathrm{lo:} \mathrm{"Articulo}$ 29. Procesos sometidos a la justicia ondinaria o contencioso administrativa. El tribunal de arbitraje es competente para resolver sobne su propia competencia y su decisión prevalece sobre cualquier otra proferida en sentido contrario por un juc: ordinario o contencioso administrativo. Lo anteriar, sin perjuicio de lo previsto en el recurso de anulacion. Si del astunto objeto de arbitraje estuviere conociendo la justicia ordinaria o la contencioso administrativa, y no se hubiere proferido sentencia de única o primera instancia o terminado por desistimiento, transacciön o conciliaciön, el tribunal arbitral solicitará al respectivo despacho judicial la remisión del expediente y éste deberá proceder en consecuencia. Si dicho arbitraje no conctuyere con laudo, el proceso judicial continuarí ante el juez que lo venia conociendn, para lo cual el presidente del tribunal devolverà el expediente. Las pruebas practicadas y las actuaciones surtidas en el trámite arbitral consentarán su validez". 
Otras normas de la ley fijan las circunstancias en que los árbitros pueden tratar con órganos jurisdiccionales: por ejemplo, el Art. 15 que se refiere a las objeciones a la imparcialidad de un árbitro único o de la mayoría de árbitros en un tribunal arbitral colegiado. En este supuesto, corresponderá al juez civil atender el incidente; el Art. 32 relativo a las medidas cautelares, autoriza a los árbitros a comisionar a los jueces civiles o a los jueces administrativos la práctica de tales cautelas; el Art. 42 que trata sobre el trámite del recurso de anulación que se planteare contra laudos arbitrales. Esta norma confirma la restricción impuesta a los órganos jurisdiccionales para interferir en un arbitraje, puesto que prohíbe a los jueces tramitar el recurso de anulación cuando fueren extemporáneos o cuando no se hubiere fundamentado en las causales taxativamente previstas en la ley.

A diferencia de la Ley española que contiene una norma que enumera los casos en que es posible la comunicación formal entre árbitros y jueces, la ley colombiana prevé esta situación en varias disposiciones, pero con un sentido restrictivo: la relación procesal de árbitros y jueces solamente puede verificarse en los casos previstos en la ley.

Como analizaré a continuación, el sistema arbitral que instituye la Ley de Arbitraje y Mediación vigente en Ecuador, no se aparta de estas previsiones que trae el derecho comparado.

\section{LA Alternabilidad DEL aRbitraje EN LA LEGiSla- CIÓN ECUATORIANA}

Al igual que la Constitución anterior, la que actualmente rige en Ecuador reconoce al arbitraje como un método de solución de conflictos "alternativo" (Art. 190). Esta calificación ya venía establecida en la Ley de Arbitraje y Mediación de 1997. En ella se definió al sistema arbitral como "un mecanismo alternativo de solución de conflictos al cual las partes pueden someter de mutuo acuerdo, las controversias susceptibles de transacción..." (Art. 1).

Revista Ecuatoriana de Arbitraje 
Del sentido de estas normas queda claro que el carácter "alternativo" se predica del arbitraje como tal, esto es, del sistema arbitral en su conjunto, sin excluir a ninguno de los elementos que lo conforman: los árbitros, el procedimiento y el laudo que pone fin a la controversia, son los elementos sistémicos que integran el arbitraje y vienen investidos todos ellos de alternabilidad respecto de los jueces, cortes y tribunales, del procedimiento civil y del régimen de impugnación de los decretos, autos y sentencias que expiden los jueces.

La jurisdicción convencional que corresponde a los tribunales de arbitraje nace del acuerdo de voluntades denominado "convenio arbitral", definido en el Art. 5 de la Ley de Arbitraje y Mediación. Este carácter alternativo determina que, una vez que las partes hubieren convenido en un documento someter sus diferencias susceptibles de transacción a la decisión de un árbitro, la jurisdicción convencional, distinta de la jurisdicción legal, deberá sustituir a esta última.

A partir de esta precisión se concluye que la alternabilidad del arbitraje le convierte en un sistema distinto del que corresponde a los procesos judiciales. Las normas que regulan al arbitraje son especiales y diversas, se rigen por un principio de especialidad, y por institutos y métodos de interpretación que le son propios como el de competencia de la competencia, separabilidad de la cláusula de compromiso arbitral, pro arbitraje etc., ya instituidos en la Ley Modelo CNUDMI/UNCITRAL y en todas las legislaciones que se han inspirado en ella.

De la "alternabilidad" establecida en la Constitución de la República, derivan al menos tres consecuencias jurídicas: (i) los árbitros no son órganos de administración de justicia; (ii) las reglas del procedimiento arbitral son distintas de las del procedimiento judicial; $y$, (iii) Ningún órgano judicial ni de control de constitucionalidad puede pronunciarse sobre el fondo de una controversia decidida por árbitros. 


\subsection{Los árbitros no son órganos de la Función Judicial del Estado}

Esta es la primera consecuencia de la alternabilidad del sistema. Los árbitros que resuelven controversias, bien fuere en derecho o bien fuere en equidad, no son órganos de la Función Judicial ni ejercen potestad pública jurisdiccional. Su atribución para juzgar y resolver una controversia comporta una jurisdicción de naturaleza convencional, esto es, que no obstante contar con reconocimiento legal, sus atribuciones nacen de la voluntad de las partes expresadas en un convenio arbitral. $\mathrm{Y}$ el ámbito de esa facultad para componer y decidir la controversia viene limitada por la voluntad de las partes.

En el auto que la Primera Sala de lo Civil de la Corte Superior de Justicia expedido el 27 de enero de 2006, dentro del juicio de competencia REPSOL-SOCIETYSEG, los Ministros de esa Sala analizaron este tema y señalaron que, aunque la atribución de los árbitros tenga un antecedente mediato en la ley que delega la función de juzgar, el fundamento inmediato de su actuación es el acuerdo celebrado entre las partes.

Cuando el Código Orgánico de la Función Judicial señala que los árbitros ejercerán funciones jurisdiccionales "de conformidad con la Constitución y la ley" (Art. 7 , inc. 4), no ha convertido por ello a los árbitros en jueces, ni a los laudos arbitrales en sentencias. El sentido de esa norma no es otro que reafirmar la facultad que corresponde a todo árbitro para juzgar controversias y que ésta encuentra cobertura legal en las previsiones de la Constitución y de la ley que reconocen el arbitraje. Tal disposición no desconoce que el ejercicio válido de la función de árbitro sea indispensable la existencia de un convenio arbitral, esto es, la voluntad coincidente de las partes para renunciar a la jurisdicción ordinaria y someter sus diferencias a la decisión de los árbitros.

Las reglas del procedimiento arbitral son distintas de las del procedimiento judicial. 
Una segunda consecuencia de la alternabilidad del arbitraje y que mayor resistencia encuentra entre jueces y árbitros, es que el régimen procesal arbitral se sujeta a normas adjetivas específicas que son propias del arbitraje, diferentes de las aplicables a los juicios ordinarios.

Consecuencia de este carácter del arbitraje es el derecho de las partes para modificar las reglas de procedimiento, según su mejor conveniencia ${ }^{10}$. Esto significa que en el convenio arbitral los contratantes podrán acordar libremente las normas de sustanciación del juicio arbitral, sin más limitación que una observancia estricta del principio de igualdad procesal, contradicción, derecho de defensa y garantías del debido proceso ${ }^{11}$.

El Art. 38 de la Ley de Arbitraje y Mediación ratifica esta conclusión con una previsión reiterativa de este trascendental punto de derecho: el arbitraje se sujetará a la Ley de la materia, a las normas de los centros de arbitraje, "al determinado en el convenio arbitral o al que las partes escojan"12.

Si el Art. 37 de la Ley de Arbitraje y Mediación señala que las reglas del procedimiento civil son aplicables supletoriamente a los arbitrajes en derecho, no hace sino confirmar la especialidad y alternabilidad del arbitraje, porque tal aplicación es solamente "supletoria" y para los casos de silencio de la ley o silencio de la voluntad de las partes. De esta norma se infiere que el acuerdo

10. Según cl análisis que consta a continuación, el Art. 38 de la Ley de Arbitraje y Mediación prevé que las partes pueden escoger las reglas de procedimiento del arbitraje. Esta disposición de la ley ecuatoriana ticne como antecedente el Art. 19 de la Ley Modelo de ta CNUDMI/UNCITRAL que trae el siguiente tex10: "Articulo 19. Determinación del procedimiento Con sujecioin a las disposiciones de la presente Ley: las partes tendrán libertad para convenir el porocedimiento a que se hasa de ajustar el tribunal arbitral en sus actuaciones..."

11. El control de que las normas de procedimiento estipuladas en el convenio se ajusten a estos principios corresponderá exclusivamente al tribunal de arbitraje que declare tener competencia para dirimir un conflicto al amparo de csas normas.

12. El Art. 38 de la Ley de Arbitraje y Mediación trata sobre el procedimiento con el siguiente texto: "Art. 38. - El arbitraje se sujetará a las normas de procedimiento señaladas en esia Ley, al procedimiento establecido en los centros de arbitraje, al determinado en el convenio arbitral o al que las partes escojan, sin perjuicio de las normas supletorias que sean aplicables". Es de subrayar que la norma no ha impuesto limitaciones al derecho de los contratantes de fijar las reglas de procedimiento que a bien tuvieren, desde luego, sin que esas normas pucdan negar el principio de contradicción, la tutela judicial efectiva, el derecho de defensa y las demás garantias del debido proceso. 
expresado en el convenio arbitral o en otro momento procesal tiene prevalencia sobre las normas del Código de Procedimiento Civil, con lo cual se está frente a la más clara consecuencia jurídica del carácter alternativo del sistema.

La "alternabilidad" consagrada constitucionalmente está desarrollada en la Ley de Arbitraje y Mediación cuando establece que contra un laudo arbitral no es admisible ningún recurso que no sea el horizontal de aclaración o de ampliación, y la única acción establecida para impugnar la decisión de los árbitros sea la de nulidad del laudo (Art. 31). De ahí que la aceptación a trámite de recursos de apelación contra sentencias de los Presidentes de las Cortes Provinciales de Justicia que ya han resuelto sobre la nulidad de un laudo arbitral, o de recursos de casación respecto de tales sentencias, comporte una grosera e inaceptable manipulación del sistema arbitral, una negación antijurídica de su carácter alternativo, en otras palabras, una violación del artículo 191 de la Constitución y del artículo 31 de la Ley de Arbitraje y Mediación.

Del carácter alternativo del arbitraje se desprende que los laudos que dictan los árbitros no sean sentencias de un juez ordinario sino solamente para los efectos de su ejecución, tal como prevé el Art. 32 de la Ley de Arbitraje y Mediación. Esta norma manda que las partes de un proceso arbitral cumplan lo decidido por los árbitros y que tal decisión pueda ser impuesta por las vías de apremio establecidas por la legislación procesal. Por ello, resulta contrario al carácter alternativo del sistema asimilar las vías de impugnación y de recursos procesales previstos en la justicia ordinaria como si un laudo arbitral fuere una sentencia del juez civil.

Ningún órgano judicial ni de control de constitucionalidad puede pronunciarse sobre el fondo de una controversia decidida por árbitros.

El carácter alternativo del sistema arbitral y el que las vías de impugnación de los laudos sean específicas y distintas de los pre- 
vistos para sentencias, autos y decretos de los jueces, trae esta otra consecuencia, quizás la más importante para la efectividad del método compositivo al que denominamos arbitraje: que las decisiones adoptadas por un Tribunal de Arbitraje para poner fin a una determinada controversia, no pueden ser revisadas por el fondo, por ningún otro órgano.

En otras palabras, mediante la acción de nulidad de un laudo arbitral que prevé el Art. 31 de la Ley de la materia, los Presidentes de las Cortes Provinciales de Justicia deberían limitar su pronunciamiento a establecer, sobre el mérito del expediente, si han ocurrido o no las causales previstas en esa norma y, consecuentemente, si el laudo pronunciado está o no viciado de nulidad. En este último caso, el Presidente de la Corte Provincial que encontrare mérito para anular un laudo, remitirá el expediente al Centro de Arbitraje de origen o al Tribunal Arbitral independiente para que corrija el señalado vicio. Lo que la alternabilidad del sistema y la letra del Art. 31 de la Ley de Arbitraje impiden a los Presidentes de las Cortes Provinciales es resolver sobre el objeto de la litis arbitral que ya fue materia de pronunciamiento de los árbitros.

Por otro lado, las providencias interlocutorias, declaratorias de competencia o incompetencia de un Tribunal Arbitral o laudos no son susceptibles de impugnación a través de las garantías jurisdiccionales que han previsto los Arts. 87, 88, 93 y 94 para la Constitución de la República, para la protección de derechos constitucionales. Es decir que la alternabilidad del arbitraje prevista constitucionalmente, determina que tampoco proceda la acción extraordinaria de protección ni medidas cautelares contra laudos, ni contra las decisiones adoptadas por un tribunal de arbitraje sobre su competencia, ni sobre las órdenes procesales para sustanciar el proceso arbitral, dado que esas decisiones adoptadas en un juicio arbitral no pueden ser revisadas por ningún órgano jurisdiccional ni de control de constitucionalidad que para estas materias, no existe. 
No solamente el carácter alternativo del sistema arbitral lleva a esa conclusión ${ }^{13}$.

La historia de la aprobación del Art. 191 de la Constitución que consta en las Actas 78 -páginas 4 a 11-y 82 -página 25- de la Asamblea de Montecristi, deja en evidencia que el legislador constituyente discutió la inclusión del control de constitucionalidad respecto de las decisiones adoptadas en métodos alternativos de solución de conflictos y que finalmente, en el segundo debate, eliminó lo que habría sido una inaceptable contradicción: por un lado el Art. 191 habría establecido la alternabilidad del arbitraje y por otro habría previsto la impugnabilidad de las decisiones de los árbitros como si se tratase de sentencias o de autos firmes que expiden los jueces ordinarios.

Para evitar la contradicción, la Asamblea de Montecristi que aprobó el Art. 191, eliminó todo control de constitucionalidad en estas materias, de manera que para resolver un litigio sobre materia transigible, cualquier referencia o aplicación de normas constitucionales quedará sujeto exclusivamente a la facultad interpretativa y resolutiva de los árbitros y aún en el evento de error, esa decisión no podrá ser modificada ni revocada por la Corte Constitucional, dado que no existe jurídicamente ningún recurso ni acción contra las decisiones de los árbitros, que no sea la acción de nulidad del laudo.

13. En la Revista No. 3 del Instituto Ecuatoriano de Arbitraje se publicó el artículo titulado "La Constittrcion de $2008 \mathrm{y}$ el Arbitraje seguin la ley ecuatoriana: Análisis de dos problemas que surgen antes que del texto constitucional, de su cquirocada aplicacion"." En ese documento destaqué cuatro argumentos de derecha que lievaban a la conclusión de que sobre un laudo o respecto de cualquier decisión que adoptan los àrbitros no procede una acción extraordinaria de protección. En sintesis, estos argumentos son los siguientes: a) inexistencia de norma que hubiere contemplado que sobre laudos arbitrales exista control de constitucionalidad; b) la lístoria de la aprobación del $\mathrm{Ar}$. I9I de la Constitución en que se advierte que la Asamblea Constituyente climinó del texto de ese articulo la frase relativa al control de constitucionalidad de las resoluciones adoptadas en métodos alternativos de solución de conflictos; c) la alternabilidad del arbitraje que impide aplicar sobre laudos $\mathrm{cl}$ mismo régimen de impugnación que se ha previsto para sentencias; d) el objeto litigioso en un juicio arbitral se refiere a derechos transigibles y no a la declaración de dercchos constitucionales. 


\section{ANTIJURIdicidad de los "ANUNCIOS DE COMPETEN- CIA" DE UN JUEZ ORdinario A UN TRIBUNAL DE AR- BITRAJE}

Si partimos de las premisas expuestas en este análisis, de que por definición de la Constitución (Art. 191) y de la ley (Art. 1) el arbitraje es un sistema alternativo al de la Función Judicial, de que el procedimiento arbitral es específico y distinto del proceso judicial, de que los árbitros -aunque tengan atribuciones jurisdiccionales- no son órganos de la Función Judicial y de que ningún juez, tribunal, Sala o Corte de Justicia ni de control de constitucionalidad puede pronunciarse sobre el fondo de una controversia decidida por árbitros, podríamos plantear la siguiente interrogante: ¿La comunicación procesal que entre jueces y árbitros está limitada a los casos previstos en la Ley de Arbitraje y Mediación, autoriza a los jueces a promover conflictos de competencia en contra de tribunales de arbitraje?

Esta pregunta quedó planteada y respondida en la comunicación que el árbitro único del juicio arbitral No. 052-04 planteado por la compañía SOCIETYSEG en contra de REPSOL, remitió al Juez Décimo Primero de lo Civil de Pichincha en febrero de 2005, que ha sido analizado anteriormente, cuya respuesta tuvo este sentido: la comunicación procesal entre órganos judiciales y tribunales arbitrales es limitada; está circunscrita a las previsiones establecidas en la norma de derecho, de ahí que cualquier anuncio de competencia del Juez Civil, de Trabajo, de Inquilinato, de contravenciones, de una Sala de la Corte Provincial o Nacional dirigido a un Tribunal de Arbitraje o a un Centro de Arbitraje, carecería de fundamento y resultaría manifiestamente antijurídico.

El procedimiento relativo al juicio especial de competencia que regula el Código de Procedimiento Civil (Arts. 848 a 855) está establecido para dirimir conflictos de competencia entre órganos de la Función Judicial, y de ninguna manera puede extenderse a los tribunales de arbitraje puesto que no forman parte de esa Función del Estado. 
La aplicación del principio de "competencia de la competencia" establecido en el Art. 22 de la Ley de Arbitraje y Mediación, sustenta esta conclusión. Según la acepción "positiva" de ese principio, solamente a los árbitros corresponde la facultad de declarar sobre su propia competencia, en la Audiencia de Sustanciación; y en su acepción "negativa" se prohíbe o excluye a cualquier órgano de justicia interferir en esa declaratoria. Así es como la doctrina define al señalado principio que está consagrado en el Art. 22 de la ley ecuatoriana.

El principio de competencia de la competencia del Art. 22 es no solamente el reflejo de la influencia de la Ley Modelo de la CNUDMI/UNCITRAL. Se enmarca en una tendencia universal del derecho comparado y es la expresión de la alternabilidad del arbitraje que trae el Art. 191 de la Constitución.

La resolución que finalmente adoptó la Corte Superior de Justicia de Pichincha en el Juicio Especial de Competencia planteado ante el Juez Décimo Primero (caso REPSOL-SOCIETYSEG) dejó sentada esta conclusión, con un análisis pertinente respecto a la alternabilidad del arbitraje. Dicho fallo enfatizó sobre la "autonomía" del sistema arbitral frente a la jurisdicción legal de los jueces. A partir de este fallo quedó definido que los órganos judiciales no pueden dirigir anuncios de competencia a los árbitros y ratificó lo actuado por el árbitro que desatendió el anuncio de competencia del Juez Décimo Primero de lo Civil Suplente de Pichincha.

Es de destacar que el auto que la Corte Superior expidió en el caso REPSOL-SOCIETYSEG no se trataba de un pronunciamiento aislado. Se enmarcaba en una línea de precedentes que de manera consistente precautelaban los principios que sostienen el arbitraje, y que han acertado en definir el principio kompetenzkompetenz, con razonamientos que dejaban entrever el cabal conocimiento que los jueces habían alcanzado respecto de las instituciones que proclama la Ley de Arbitraje de Ecuador. 
Frente a este pronunciamiento de la Corte Provincial de Justicia es necesario subrayar los casos en los cuales los órganos de la Función Judicial del Estado podrían tener comunicación con tribunales de arbitraje, análisis que estaba inserto en la respuesta que en condición de árbitro único me correspondió remitir al comentado "anuncio de competencia" que recibí del Juez Décimo Primero (Suplente).

\subsection{Casos en que un Juez puede entablar una relación pro- cesal con un Tribunal de Arbitraje}

Si atendemos la Ley de Arbitraje y Mediación, que es especial y por mandato de la Constitución de la República (Art. 191) rige en esta materia, podemos establecer que en el sistema arbitral ecuatoriano existen cuatro casos en los que un árbitro puede mantener relación procesal con órganos de administración de justicia, $\mathrm{y}$ viceversa.

El primero es el del Art. 8: cuando se presenta una demanda ante cualquier órgano de la Función Judicial y el demandado plantea excepción de incompetencia por la existencia de convenio arbitral.

En el evento de haber sido propuesta esta excepción, el juez deberá sustanciarla y resolverla, corriendo traslado a la otra parte y exigiendo a los litigantes la prueba de sus afirmaciones dentro de los tres días subsiguientes a la fecha en que se haya notificado el traslado. Aceptada la excepción deberá ordenarse el archivo de la causa, en caso contrario, ejecutoriado el auto dictado por el juez, se sustanciará el proceso según las reglas generales.

Por tanto, el sistema arbitral ecuatoriano no ha previsto el procedimiento de un anuncio de competencia entre árbitros y jueces, y ha ordenado en el Art. 8 de su ley especial, que el juez civil que conoce de una excepción de incompetencia, o bien archiva el proceso civil o bien continúa en el conocimiento del caso, sustanciándolo según las reglas generales. El árbitro no puede anunciar 
su competencia al juez civil. Si la demanda arbitral se dirigiera contra una persona que no fue parte del convenio, el afectado podrá plantear el argumento de incompetencia como "excepción" dentro del juicio arbitral, y siempre tendrá franqueado su derecho para impugnar el laudo arbitral, mediante una acción de nulidad fundamentada en la letra d) del Art. 31 que establece que el laudo es nulo cuando resolviere cuestiones no sometidas al arbitraje. Sin embargo, si un Tribunal de Arbitraje ya hubiere declarado competencia (Art. 22), ningún órgano jurisdiccional puede pretender el conocimiento de la causa arbitral.

El segundo caso de una eventual relación procesal entre jueces y árbitros está señalado en el Art. 9, que trata de la ejecución de medidas cautelares. Aún a falta de acuerdo estipulado en el convenio arbitral, las medidas cautelares pueden ser dictadas por un Tribunal de Arbitraje. Sin embargo, su ejecución corresponderá a los jueces comunes sin que ello signifique renuncia al convenio ni alteración de la competencia que los árbitros hubieren declarado tener sobre el juicio de que se trate.

El tercer caso está relacionado con la acción de nulidad del laudo arbitral de que trata el Art. 31 de la misma Ley, acción que es conocida y resuelta por los Presidentes de las Cortes Provinciales de Justicia, bajo un procedimiento especial y sumario según los términos de la norma referida, siempre que hubieren ocurrido cualquiera de las causales taxativamente establecidas en esa norma. Es de aclarar que el carácter alternativo del arbitraje inhibe a los Presidentes de las Cortes Provinciales de Justicia formular ningún pronunciamiento sobre el fondo de la controversia, debiendo limitar su pronunciamiento a si un determinado laudo es o no nulo según las causales de la ley.

El cuarto caso está previsto en el Art. 32 y se refiere a la ejecución de laudos arbitrales. Cualquiera de las partes podrá pedir a los jueces ordinarios que ordenen la ejecución del laudo, presentando una copia certificada del laudo con la razón de ejecutoria. En este caso el Juez Civil ejecutará el laudo como si se tratase 
de una sentencia ejecutoriada, siguiendo la vía de apremio, sin que pueda aceptar excepción alguna, salvo las que se originen con posterioridad a la expedición del laudo.

Ninguna otra forma de comunicación procesal distinta de los cuatro eventos que quedan señalados por la Ley de Arbitraje y Mediación, puede establecerse entre árbitros y órganos de la Función Judicial, menos aún disputas o conflictos de competencia. Tal actuación sería ilegal y no prevista en ninguna norma de la Ley de Arbitraje y Mediación, infringiría el principio de alternabilidad del arbitraje y el de competencia de la competencia.

\subsection{El caso HAMPTON COURT RESOURCES ECUADOR: un precedente peligroso para el sistema arbitral ecuatoriano}

Aunque la alternabilidad del arbitraje como fundamento del sistema y el principio kompetenz-kompetenz cuentan con protección constitucional, han sido definidos por la jurisprudencia desde hace varios años $y$, tales definiciones habían contribuido a la seguridad y certeza en el desenvolvimiento del arbitraje, la Primera Sala de lo Civil, Mercantil, Inquilinato y Materias Residuales de la Corte Provincial de Pichincha decidió apartarse no solamente de la ley sino de una tendencia que los jueces ecuatorianos habían marcado de manera consistente desde el caso REPSOL-SOCIETYSEG en mayo de 2005.

Este nuevo caso inició con la demanda arbitral planteada por los señores Lyle Smith y David Zondag en contra del Señor Glenn Allan Good, que habían suscrito un Acuerdo de Transferencia de acciones. Habían dirigido su acción arbitral equivocadamente, en contra de la compañía HAMPTON COURT RESOURCES ECUADOR S.A., que como tal persona jurídica no había suscrito el convenio arbitral inserto en ese Acuerdo. Un primer error, lamentable, por parte de los accionantes. 
El Tribunal de Arbitraje, en la Audiencia de Sustanciación, declaró su competencia para conocer de esta demanda y señaló que "resolverá posteriormente sobre su competencia para pronunciarse sobre los derechos u obligaciones de la companín HAMPTON COURT RESOURCES S.A. a la cual también se demanda". Este fue en mi apreciación, un segundo error que aparece del expediente, en este caso cometido por el Tribunal Arbitral.

Con fecha 1 de octubre de 2009, la Jueza Vigésimo Tercera de Pichincha aceptó la acción inhibitoria de competencia que planteó la compañía HAMPTON COURT RESOURCES ECUADOR y decidió anunciar su competencia a un Tribunal de Arbitraje de la Cámara de Comercio de Quito, que ya había declarado tenerla para conocer del juicio arbitral signado con el número 087-08 SMITH, ZONDAG contra GLENN ALLAN GOOD y que habia postergado su decisión respecto de la compañía HAMPTON COURT RESOURCES S.A.

Aunque tenga opinión discrepante con la decisión adoptada por el Tribunal de Arbitraje, dado que el Art. 22 de la Ley de Arbitraje y Mediación dispone que la declaratoria de competencia se hará en el momento procesal de la audiencia de sustanciación y no en otro posterior, es de destacar que solamente a los árbitros que integraron ese Tribunal correspondía resolver sobre su propia competencia. Este es la expresión del principio de "competencia de la competencia".

Sin embargo, aquello que pudo haber sido un error del Tribunal Arbitral al momento de aplicar el Art. 22 de la Ley, no significaba aún que la decisión que habrían de adoptar en el laudo, necesariamente comprendería a la persona jurídica que no era parte del convenio y, bajo el supuesto de que así habría sido, correspondía a HAMPTON COURT RESOURCES S.A. defender ante el Tribunal Arbitral su excepción de incompetencia y, finalmente, plantear una acción de nulidad del laudo fundamentado en la causal de la letra d) del Art. 31 si es que el laudo arbitral hubiere comprendido a la persona jurídica que no era parte del convenio arbitral. 
Elevado el juicio de competencia en virtud del sorteo legal, le correspondió su conocimiento a la Primera Sala de lo Civil y Mercantil, Inquilinato y Materias Residuales de la hoy denominada Corte Provincial de Justicia de Pichincha. Esa Sala estaba integrada por la Dra. Beatriz Suárez Armijos que actuó como Juez Ponente y por los Jueces doctores Alberto Palacios Durango y Juan Toscano Garzón.

La Sala por decisión de mayoría (Dra. Beatriz Suárez Armijos y Dr. Alberto Palacios Durango) resolvió pronunciarse sobre la competencia que ya habían declarado los árbitros en el juicio 087-08, restringiendo el ámbito respecto del cual debían pronunciarse en el laudo arbitral, para lo cual excluyeron del arbitraje a la compañía HAMPTON COURT RESOURCES y dejaron a salvo -menos mal- la atribución de los árbitros para "pronunciarse libremente en cuanto cobija al convenio arbitral".

Esta decisión se fundamentó en lo siguiente: (i) que la postura del Tribunal Arbitral de desestimar el anuncio de competencia "pugna con el organigrama jurídico institucional vigente en el Ecuador"; (ii) que los Arts. 169 y 190 de la Constitución, 8, 17 y 22 de la Ley de Arbitraje y Mediación no han otorgado a los Tribunales Arbitrales «la condición de Estado paralelo, exento de control de legalidad por parte de los Tribunales Ordinarios pues de acuerdo con las normas que se citan, todos los procedimientos y facultades son 'de conformidad con la ley'»; (iii) que los árbitros no pueden desconocer, menos desatender los procesos correlativos a su ejercicio jurisdiccional y que entre esas normas está el juicio de competencia prevista en el libro II Título II sección 24 del Código de Procedimiento Civil ${ }^{14}$; (iv) que el Art. 22 de la Ley

14. Con relación a este tema, el considerando TERCERO de la sentencia comentada sustenta sus afirmaciones asi: "que en función del principio dispositivo, opera como derecho ciudadano a cuy'o impulso responde la Funcion Judicial a través de sus funcionarios. Por tanto, nat ha hecho el Tribunal demandado, en despreciar el requerimicnto judicial, que merece todo el respeto, tanto más que no se trata de uma actividad oficiosa de la señora Jueza, ni una pretensión suy a (como dice el Tribunal provocado) sino tuna demanda formalmemte presentada, a la que obligatoriamente la Judicatura debio tramitar". Nótese el elemento emocional antes que juridico, que consta en la afirmación de que el Tribunal de Arbitraje no debiỏ "despreciar" el "requerimicnto judicial" que "merece todo respeto". Llami la atención que la Sala de la Corte Provincial confunda el "anuncio de competencia" de un juicio especial con el "requerimiento judicial" que es instituto distinto. Además, desestimar un anuncio de competencia ilegal como consideró el Tribunal Arbitral no comporta una falta de respeto a una Jueza que ya se irrespetó a si misma actuando al margen del derecho. 
de Arbitraje y Mediación no dice que los tribunales arbitrales estén exentos de sujetarse al procedimiento del juicio de competencia y que rige el mandato del Art. 8 del Código Civil, norma en virtud de la cual "A nadie puede impedirse una acción que no esté prohibida por la ley" y que si en la Ley de Arbitraje y Mediación no se ha previsto la forma de proceder con relación a juicios de competencia "la lógica jurídica determina que ha de procederse en la forma establecida en el Código de Procedimiento Civil". Asumir lo contrario significaría "colocar al sujeto procesal al margen de la ley"15.

A continuación analizaré algunos de los más importantes argumentos expuestos en el fallo de la Corte Provincial y que me he permitido calificarlos de inconsistentes, por las razones que dejo consignadas a continuación.

\subsubsection{Comentario a la sentencia del juicio de competencia planteado por HAMPTON COURT RESOURCES ECUA- DOR}

Aunque el desconocimiento de la ley no excusa a persona alguna, menos al Juez llamado a aplicarla, el error en que incurrió la Juez Ponente en la sentencia comentada, deja en evidencia un retroceso con relación al arbitraje, un profundo desconocimiento de los fundamentos en virtud de los cuales la Sala debió, en mi opinión, desestimar el juicio de competencia que se había planteado. El hecho resulta llamativo si se considera que desde la expedición de la Ley de Arbitraje y Mediación han transcurrido más

15. Uno de los extravios más frecuentes sobre el principio de altemabilidad det sistema arbitral, es la de asimilación del árbitro a la condición dei juez. En el considerando SEGUNDO de la sentencia, los Jucces vaciaron de contenido al principio de competencia de la competencia y asimilaron al árbitro $\mathrm{en} \mathrm{el}$ papel del juez civil con la siguiente afimación: "Es menester difenenciar la capacidad que tienen los tribunales arbitrales dentro de los procesos de resolser sobre su propia competencia de acuento con los articulos 8 y 22 de la Ley de la materia. en una práctica asimilable a la que tienen todos los jueces arlinarios para 'asegurar stu competencia', como medio de cumplir con las solemuidades sustanciales en orien a presenar la valide del pmeeso: cuando aquella ha sido propuesta como excepción de incompetencia del juez". Esta afirmación de la Sala desconoce el significado que tiene en el orden juridico el principio en virtud del cual los árbitros son los únicos autorizados por la ley para pronunciarse sobre su propia competencia, principio con el cual, el sistema juridico apuntala la alternabilidad del sistema arbitral frente al orden jurisdiccional y excluye toda posibilidad de que se entablen juicios de competencia entre jueces y árbitros. 
de catorce años y que estos temas han merecido sentencias esclarecedoras de la misma Corte Superior de Justicia de Pichincha, como la del caso REPSOL-SOCIETYSEG de enero de 2006.

La postura del Tribunal Arbitral no pugna con el organigrama institucional vigente en el Ecuador, porque no es parte de ese organigrama. Más aún, el sistema arbitral como tal ha sido reconocido no solamente por las normas de una ley especial, sino por disposiciones constitucionales.

Los tribunales de arbitraje no son "Estado paralelo" por el hecho de defender aquello que la Constitución y la ley califican de "alternativo". Es decir, la jurisdicción convencional que ejercemos los árbitros tiene carácter paralelo, distinto, diferente, "alternativo" de los órganos de la Función Judicial. Defender este principio no es crear ningún Estado si es que la propia Constitución que rige en el Estado ecuatoriano, así lo ha establecido. No entender así la alternabilidad del arbitraje sería burlar el Art. 191 de la Constitución y asimilar a los tribunales de arbitraje en el organigrama de la función judicial como parecería sugerir la sentencia comentada.

Por otro lado, la afirmación de que todos los procedimientos que adopte un tribunal de arbitraje deben ser "de conformidad con la ley" no está en discusión. Sin embargo, esta premisa no autoriza a la interpretación de que los conflictos de competencia con árbitros deban quedar sujetos al juicio especial del Código de Procedimiento Civil, puesto que de conformidad con la Ley de Arbitraje son los árbitros los llamados a pronunciarse sobre su propia competencia (Art. 22); y si los árbitros violaren el convenio y comprendieren en su laudo a una persona que no firmó ese convenio, el afectado podrá demandar la nulidad del laudo arbitral. Estos son los eventos "conformes con la ley" que el fallo comentado no razonó con la suficiencia y acierto en que lo hizo el voto salvado del Dr. Juan Toscano Garzón. 
Adicionalmente, la alternabilidad del arbitraje no significa que las actuaciones de los árbitros estén exentas de un control de legalidad como sugiere el primer considerando de la sentencia. El simplismo de esta apreciación de los jueces queda respondido por lo dispuesto en el Art. 31 de la Ley de Arbitraje y Mediación que prevé que contra un laudo que hubiere incurrido en una de las causales de esa norma, procede una acción de nulidad ante los Presidentes de las Cortes Provinciales y ese es el único control que establece el sistema legal en el Ecuador. Por tanto, la ley especial si ha previsto un régimen de control de los laudos.

Sobre la sujeción al juicio de competencia que el Código de Procedimiento Civil ha establecido exclusivamente para órganos jurisdiccionales, queda como respuesta el análisis de este artículo. Se debe destacar que la sentencia ni por asomo analizó un punto de derecho que ha sido ampliamente debatido dentro y fuera del país respecto a la extensión del convenio arbitral a partes no signatarias ${ }^{16}$. Habría sido muy útil conocer qué opinión jurídica tenían los señores jueces del voto de mayoría sobre un tema tan trascendente.

\section{Conclusión}

En síntesis, este es un fallo apartado de los fundamentos constitucionales y legales que sustentan al arbitraje ecuatoriano, en la que los mencionados jueces -con excepción del Dr. Juan Toscano que salvó su voto- decidieron romper la alternabilidad del sistema arbitral, tergiversar el principio de competencia de la competencia y el significado que tienen estas instituciones no solamente para la Constitución y la ley, sino para la doctrina, la legislación comparada y los pronunciamientos que con más fundamento jurídico dictó la Corte Superior de Justicia de Pichincha en épocas pasadas.

16. Sobre esta materia recomiendo especialmente el articulo "Extension del Comento drbitral a partes no signatarias: Expresion de la inevitabilidad del arhitraje" "scrito con la pluma clegante y profunda que distinguiò al gran jurista peruano Dr. Jorge Santiestevan de Noriega y que esta publicado en la Revista Peruana de Arbitraje No. 8/2009, pp. 17-49. 
Por otro lado, llama la atención que el Dr. Alberto Palacios, que presidió la Sala de lo Civil que resolvió el caso REPSOL-SOCIETYSEG en el año 2005-2006 y que había dado aquel pronunciamiento memorable en defensa de la alternabilidad del arbitraje, del principio kompetenz-kompetenz y de la separabilidad de la cláusula arbitral, haya modificado su acertada apreciación jurídica por una postura contradictoria, que desdice todos los fundamentos del fallo anterior y que no los consideró en esta sentencia para explicar por qué los principios que explicó en el fallo anterior los desestimó en este fallo más reciente.

Con relación al Dr. Juan Toscano Garzón, sin embargo de que no integró la Sala que conoció el juicio REPSOL-SOCIETYSEG, dio su voto salvado en el caso HAMPTON COURT RESOURCES ratificando aquel pronunciamiento y con un meritorio análisis enfocó las razones por las cuales se separaba del voto de mayoría. El Dr. Toscano defendió el sentido genuino del Art. 22 de la Ley de Arbitraje: decidió que habiéndose declarado competentes los árbitros para conocer de la causa, no correspondía a la justicia ordinaria interferir en el juicio arbitral, y que si en el laudo arbitral se incluyera a una persona jurídica que no firmó el convenio arbitral, la parte afectada podía plantear una acción de nulidad conforme la previsión del Art. 31 de la Ley de Arbitraje y Mediación.

Este voto salvado del Dr. Toscano ofrece una esperanza de que el arbitraje pueda encontrar en los jueces una reflexión jurídica apropiada para defender aquello que la Constitución y la Ley han establecido a favor de este método alternativo. 